\title{
ДИСКУССИИ
}

\section{Модель для анализа работы совета директоров: роль внутренних и внешних функций независимых директоров}

\begin{abstract}
Давид Рассел ${ }^{33}$
Канадский исследователь советов директоров Лебланк указывает на то, что распространяющееся повсеместно мнение относительно высокой роли структуры совета не отвечает насущным вопросам его эффективности. Исследование процессов, происходящих в совете, показывает, что исполнительные директора, и независимые директора в особенности, должны обладать соответствующей компетенцией, для того чтобы их деятельность была эффективной. Однако следует заметить, что в данном вопросе недостает методологии анализа, которая помогла бы исследователям определить и классифищировать именно те знания, навыки и умения, которыми обязан владеть эффективный директор. Посредством использования основополагаюших взглядов теории управления персоналом, а также теории человеческого капитала в данной статье предлагаются критерии оценки деятельности независимых директоров компании. В данной работе уделяется особое внимание анализу влияния непредвиденных обстоятельств $u$ случайностей на вылвление наиболее полезных компетенций конкретного директора, и в особенности - жизненного ичкла организации как условной переменной. Более того, представленный здесь взгляд предоставляет возможность независимому директору внести свой вклад в деятельность фирмы не только в области руководства компанией или при выполнения роли, требующей сочетания двух различных позищий, но также в качестве компетентного деятеля, способного $\kappa$ познанию бизнеса компании, который сможет плодотворно участвовать в разработке и успешном выполнении ее стратегии.
\end{abstract}

$J E L: G 34$

Ключевые слова: корпоративное управление, советь директоров, неисполнительные директора, компетентностный подход.

Независимость (директора)... ни в коей мере не может сравниться с важностью того, каким уровнем компетенциии он обладает.

Ричард Лебланк

\section{1. Вступление}

Последнее десятилетие продемонстрировало крушения многих компаний в различных частях мира, которые фокусировали внимание своих инвесторов, правительств и в целом широкой общественности на вопросах корпоративного управления. Названия «Enron», «WorldCom Inc.» и «Global Crossing» стали синонимами корпоративного должностного преступления и олицетворяют собой попытки некоторой корпоративной элиты подвергнуть обману своих акционеров и общество в целом. Результатом стал прогнозированный кризис корпоративного управления с вполне объяснимыми призывами к проведению реформ в структурах и системах корпоративного управления.

\footnotetext{
${ }^{33}$ Ecole Superior de Gestion of Paris Graduate School of Management - Paris, France Выпуск \#2(6), 2008 
В Соединенных Штатах, например, такие «сторожевые псы» экономики, как Комиссия по ценным бумагам и биржам (SEC) и Конгресс США, провели ряд реформ в управлении корпорациями, с тем чтобы сделать работу управленческой элиты более прозрачной, а ее саму - ответственной за ее действия. Постановление Сорбейнса-Оксли от 2002 года параллельно с изменениями, введенными в правила корпоративного управления и принятыми Нью-Йоркской фондовой биржей, Национальной ассоциацией дилеров с ценными бумагами (NASD), а также Американской фондовой биржей (AMEX), вызвались защитить инвесторов посредством требования более точного и полного раскрытия корпоративной информации. Многие реформы, осуществленные этими организациями, также имели своей целью сконцентрироваться на работе советов директоров в целом и независимых директоров (non-executive directors, NEDs) в частности, так как последние занимают такое положение в иерархии компаний, которое позволяет им осуществлять текущий контроль за работой менеджеров. Постановление Сарбанеса-Оксли от 2002 года требует от зарегистрированных на бирже компаний формировать свои советы директоров в основном из неисполнительных директоров.

Такое пристальное внимание к советам директоров и независимым директорам в глазах общественности привело к увеличению академических исследований, относящихся к этому, по-видимому, могущественному, но труднопостижимому, институту корпоративного управления. В последнее время подробному изучению подверглись механизмы работы советов директоров с целью определения их влияния на фирму и её деятельность. Анализ влияния директоров стал наиболее трудным в исследовании, и их большая часть не имела никаких конкретных выводов.

Такое отсутствие выводов относительно влияния советов директоров правомерно ставит перед нами задачу более скрупулезного рассмотрения не только совета как такового, но также и тех, из кого он состоит. Исследование структуры советов было дополнено исследованием процессов его работы в попытке проникнуть внутрь «черного ящика», т.е. современного совета директоров. То, что многие исследования не сопровождаются конкретными выводами, объясняется их фокусированием в большой степени на структуре совета, а не на стоящих за ним опыте и знаниях конкретных людей. Более того, недавние исследования рассматривали совет директоров как нечто, находящееся в вакуумной среде, без учета всего спектра контекстуальных факторов, которые могут оказывать непосредственное влияние на роль советов директоров в деятельности компаний. К ним относятся роли, которые совет должен осуществлять, а также влияние промышленных условий на исполнение данных ролей.

И академические исследователи, и практики все чаще подчеркивают потребность в «компетентных директорах», не давая подробного описания того, какими именно компетенциями должны обладать советы директоров, с тем чтобы сделать свою работу эффективной. Вышеупомянутые скандалы стали поводом для, возможно, чрезмерного выделения руководящей роли независимых директоров, и это послужило размыванию правильного понимания их действительной ценности для совета, так же как и той роли, которую он или она выполняют.

Множество исследований относительно советов директоров скорее проводится сквозь призму одного вида деятельности конкретного совета, а не посредством всестороннего изучения набора ролей. Многие исследования особо отмечают направляющую роль неисполнительных директоров, но оставляют в стороне вопрос, какими компетенциями они должны владеть, чтобы их руководство было эффективным. Вдобавок исследования, определяющие типы компетенций, которые позволяют неисполнительным директорам эффективно выполнять другие роли, такие как принятие стратегических решений и предоставление консультаций, практически отсутствуют. Некоторые ученые и практики в дополнение к выделению руководящей роли независимых директоров указывают на тот факт, что последние способствуют увеличению стоимости фирмы тем, что являются «связующим» звеном между фирмой и её внешним окружением. Удивительно, что так мало 
была исследована внутренняя ресурсная функция директоров. Исследование чаще строилось вокруг изучения роли, связанной с мониторингом фирмы и разработкой стратегии, а не «связующей роли».

В этой статье предоставлена методология анализа воздействия независимых директоров на фирмы, выходящая за рамки рассмотрения комбинации их «руководящей» и «связующей» роли. Преследуемая мною цель состоит в предоставлении основ изучения влияния неисполнительных директоров на выполнение набора ролей, покрывающих более широкий спектр деятельности совета директоров. В этой статье я попытаюсь показать, что воздействие независимых директоров на фирму демонстрируется не их долей в совете директоров, а, скорее всего, ориентацией работы таких директоров, основанной на тех компетенциях, которые они привносят в совет.

\section{2. Основы анализа}

Как было указано выше, примеры должностных правонарушений среди корпоративного руководства, совершенные за последние десять лет, привлекли внимание широкой общественности к проблемам корпоративного управления в целом и к советам директоров в частности. Деловая пресса придала огласке корпоративные скандалы [Лавелл, 2002; Нуссбаум, 2002], а ученые вынесли на обсуждение вопросы, связанные с возможными выводами и последствиями для самих советов директоров [Агилера, 2005; Трикер, 2000]. С начала 1990-х годов и по сей день в Великобритании, Соединенных Штатах и в других странах «сторожевые псы» рыночной экономики устанавливают юридические нормы и порядок, применимые в отношении советов директоров. Это привело к значительному увеличению числа независимых директоров в правлениях компаний (Комитет по финансовым вопросам корпоративного правления, 1992 год; Комиссия по ценным бумагам и бирже, 2003 год). Конгресс Соединенных Штатов принял в 2002 году закон (Акт Сарбанеса-Оксли), который юридически закрепил важные реформы в области практики корпоративного правления, нацеленные на работу советов директоров в частности.

Эти события направили внимание ученых к изучению проблем взаимосвязи, существующей между советами директоров и системой корпоративного управления. В свете предпринятых попыток реформирования процесса руководства ученые присоединились к дебатам относительно роли и значения советов директоров, и эти дебаты еще далеки от своего завершения [Далтон \&Далтон, 2005]. Появилось множество литературы, поставившей своей целью рассмотрение, среди прочих, вопросов надлежащей структуры советов директоров [Байзингер и Батлер, 1985], их роли [Гермалин и Вейсбах, 2000], соответствующих ролей исполнительных и неисполнительных директоров [Багат и Блэк, 2002] и, возможно, самого актуального вопроса из всех — влияния совета директоров на деятельность фирмы [Далтон, Дейли, Джонсон\&Ельстранд, 1999].

Начало исследований, касающихся деятельности советов директоров, однако, не относится ко времени появления нового взгляда на проблемы корпоративного управления. Проведение исследования совпало с появлением теоретических разработок в области стратегического менеджмента, относящегося к руководителям фирмы, с акцентом на внутренние и внешние факторы среды их деятельности.

Раннее исследование в области стратегического менеджмента в значительной степени базировалось на работах Бэйна [1956, 1968] и Мэйсона [1939] с акцентом на «структурноповеденческо-исполнительскую» парадигму и на внешнюю среду деятельности фирмы, в особенности на структуру данной отрасли промышленности. Подчеркивалось также значение конкурентоспособности фирмы и ее положения в отрасли. Данные представления подтверждались работой Майкла Портера два десятилетия тому назад [1980, 1985], который выдвинул идею, что деятельность фирмы фактически определяется структурой промышленности. 
Несмотря на то что ранние исследования в области стратегического менеджмента подчеркивали значение внешнего окружения фирмы, были некоторые ученые, которые свое внимание обращали на внутренние механизмы работы фирмы, особо выделяя компетенции ее высшего руководства. Научный труд Селзника [1957] исключительную роль отводит руководству фирмы и его характерным способностям. Пенроуз [1959] относил успех фирмы за счет ее ресурсов, особо выделяя значение способностей ее руководящего состава. Другие ученые [Куерт и Марч, 1963; Саймон, 1945] подчеркивали влияние поведенческих факторов управления. Чандлер [1962], в частности, обнаружил взаимосвязь между ростом компании и изменениями осуществляемыми в ее административной структуре в связи с таким ростом. Дальнейший акцент на значение внутренних структур фирмы и роль ее руководителей можно наблюдать в работе Эндрюз [1971].

Относительно исследования советов директоров, данные ранние теории способствовали строгому концептуальному разграничению между исполнительными и независимыми директорами. Считалось, что успешными являются те советы, которые способны к достижению эффективного баланса в разграничении вопросов, относящихся к внутреннему и внешнему окружению жизнедеятельности фирмы [Коуплэнд и Тоул, 1947; Кунц, 1967]. Общепринятая точка зрения состояла в том, что исполнительные директора ориентированы на осуществление деятельности компании, а независимые директора - на ее внешнее окружение [Браун, 1979; Квин, 1977). Акцент на мониторинговой и «связующей» ролях независимых директоров, казалось, совпал бы с этим взглядом.

Тем не менее существовал ряд вопросов относительно правомерности данной концептуализации ролей членов советов директоров [Буржуа, 1980; Корн/Ферри Интернэшнл 1982]. Подход к менеджменту по принципу «изнутри- вовне» (inside-out) подчеркнул деятельность фирмы, в то время как подход «извне-внутрь» (outside-in) сделал упор на стратегии, позволяющей фирме адекватно реагировать на условия окружающей среды. Исследование традиционно разделяет соответствующие роли для осуществления этих подходов между исполнительными директорами (поход inside-out) и независимыми директорами (подход outside-in) [Эндрюз, 1971; Пфеффер, 1972]. Некоторые исследователи сочли данное заключение грубым [Пфеффер, 1972; Шмидт, 1975], так как оно не отражает все аспекты деятельности независимых директоров как их реальный вклад, который они могут внести в работу фирмы. Исследование показало, что приоритеты работы директора и его вклад в деятельность компании не могут быть единственно определены положением, является ли директор исполнительным или независимым [Ванс, 1983]. Единственно возможным объяснением нехватки данных для выводов касательно влияния директоров на деятельность компании является тот факт, что исследование фокусировалось преимущественно на подсчете количества исполнительных директоров против независимых директоров и на анализе структуры совета, а не на более обоснованном с точки зрения процесса работы критерии, таком как роли советов директоров и компетенции директоров.

Многие ученые утверждают, что акцент на структуру стал причиной появления унифицированного подхода к реформе и скрыл из поля зрения тот факт, что будет сложно определить, какая структура совета директоров должна считаться идеальной. Принимая во внимание то, что фирмы рознятся одна с другой в контексте своего внешнего окружения, некоторые ученые предупреждали об опасности выдвижения предположения относительно наличия одинаковых нужд у фирм по отношению к структурам своих советов директоров и качествам, которыми должны обладать их директора [Ванс, 1978].

Эти вопросы управленческих ролей и качеств директоров исследовались в большинстве случаев через анализ структуры советов директоров, т.е. соотношения между количеством исполнительных и независимых директоров и деятельности фирмы. В последние два десятилетия многочисленные исследовательские труды пытались подтвердить наличие влияния неисполнительных директоров на деятельность фирмы [Мольц, 1988; Фосберг,1989; Шленджер и др., 1989; Гермалин и Вейсбах, 1991; Дейли и Дальтон, 1992; Берд и Хикман, 1992; Гиббс, 1993; Барнарт и др.,1994; Грейс и др., 1995; Бисли, 1996]. 
Однако не существует четкого эмпирического свидетельства существования такого влияния. Некоторые исследователи указывали на улучшение показателей деятельности фирмы по мере увеличения количества неисполнительных директоров в совете [Барнарт и др., 1994; Дейли и Дальтон, 1992; Шеленджер и др., 1989]. Другие, однако, не нашли этому подтверждения [Гермалин и Вейсбах, 1991; Фосберг, 1989; Мольц, 1988]. Некоторые исследования обнаружили наличие отрицательной взаимосвязи между количеством неисполнительных директоров в совете и показателями деятельности фирмы [Багат и Блэк, 1999; Йермак, 1986]. Проведенный метаанализ также не дал никакого заключительного ответа на поставленный вопрос. Метаанализ, проведенный в 1998 году на основе 54 исследований взаимосвязи между составом совета директоров и финансовыми показателями деятельности фирмы, также не смог выявить какой-либо связи [Дальтон, Дейли, Ельстранд и Джонсон, 1998]. Метаанализ, проведенный в 2000 году на базе 59 исследований, смог обнаружить очень незначительную взаимосвязь между составом совета директоров и финансовыми показателями деятельности фирмы [Родез, Речнер и Сундарамурту, 2000]. Таким образом, после значительной исследовательской работы, направленной на изучение эффектов влияния неисполнительных директоров на деятельность фирмы, результаты были суммированы Джеймсом Вестфалом [2002], когда он заявил: «Почти двадцатилетний опыт исследовательской работы указывает на практическое отсутствие свидетельства того, что независимость совета директоров повышает эффективнсть его работы».

Некоторые ученые ответили на такое положение дел высказыванием, что они искали источник воздействия независимых директоров на фирму не там, где следовало бы [Джиллис и Лебланк, 2003]. Они выдвинули предположение, что влияние неисполнительных директоров не может исчисляться процентным соотношением между количеством исполнительных и неисполнительных директоров. Ученые призвали к проведению исследования с акцентом на процесс работы правления, а не на его структуру [Корли, 2005; Форбс и Милликен, 1999; Гермалин и Вейсбах, 2000]. Большое количество литературы о советах директоров рассматривает те аспекты его работы, которые делают эту работу эффективной. Ученые стали все больше обращать внимание на ряд факторов, которые не получили должного рассмотрения в этой литературе: взаимосвязь роли совета директоров в процессе варьирования контекстов деятельности фирмы и уровня компетентности самих директоров.

Имеющаяся литрература действительно содержит примеры изучения ролей советов директоров [Макналти и Петтигру, 1999; Пфеффер и Салансик, 1978; Вестфал, 1999]. В то же время ученым еще только предстоит дать четкую характеристику набору ролей, которые последние должны выполнять [Ханг, 1998; Джонсон и др., 1996; Петтигру, 1992; Захра и Пирс, 1989]. Данное отсутствие консенсуса способствовало концентрации дебатов на мониторинговой функции советов директоров, особенно его неисполнительных директоров. Более того, все чаще звучали призывы к предоставлению исчерпывающей информации о перспективе появления сопряженных непредвиденных обстоятельств в подходе к процессу исполнения ролей советов директоров: не все фирмы нуждаются в одинаковом составе своих советов директоров и в выполнении последними одинаковых ролей [Гераклеус, 2001].

Другой элемент исследований, которым пренебрегали, - это компетенции директоров [Хендри, 2005; Макналти, Робертс\&Стайлс, 2005]. Теория человеческого капитала [Беккер, 1964] предполагала наличие все возрастающей роли исследований, проводимых в области менеджмента [Кастаниас и Хелфат, 2001; Нахапиети Гошал, 1998]. Некоторые исследователи призывали обратить внимание на тот факт, что способность директоров эффективно функционировать зависит от их человеческого капитала: способности директоров разрабатывать стратегию, контролировать менеджмент фирмы, а также предоставлять консультативные и юридические услуги, до некоторой степени функционировать, исходя из собственной компетенции, опыта и знаний. Словом, способность совета директоров функционировать как «совет» будет зависеть от человеческого капитала [Киел и Никольсон, 2002]. 
Очень незначительное число эмпирических исследований было предпринято с целью определения влияния человеческого капитала советов директоров на деятельность фирмы. Определенные теоретические течения подошли к проблеме: взгляд, основанный на ресурсах [Барни, 1991], ввел представление о менеджерах фирмы как уникальных ресурсах, которые приводят к повышению конкурентоспособности фирмы. Хамбрик и Мэйсон [1984] ввели понятие перспективы эшелонов высшего звена, которое позиционирует идею, что стратегия фирмы и ее деятельность будут отражать профессиональные знания и опыт работы команды топ-менеджеров. Однако эти перспективы были в основном применены по отношению к эмпирическим исследованиям управляющих высшего ранга ([Финкельштейн и Хамбрик, 1996] или к топ-менеджерам [Харви и др., 1994]. В то время как советы директоров и команды топ-менеджеров разделяют между собой некоторые одинаковые организационные функции и обязанности, совет достаточно определенно заслуживает отдельного изучения в потоке этих теоретических изысканий [Форбс и Милликен, 1999].

Недавние призывы к проведению исследования с акцентом на компетенции директоров и к тому, что в совете должны работать компетентные директора, следует дополнить постановкой эмпирического эксперимента для определения влияния человеческого капитала советов директоров на деятельность фирмы [Макналти, Робертс\&Стайлс, 2003; Пай\&Петтигру, 2005]. Во множестве работ в настоящее время особо отмечается сформировавшаяся потребность в «компетентных директорах». Однако еще очень мало сведений о том, какими именно компетенциями и в каких обстоятельствах должен обладать эффективный директор [Джиллис и Лебланк, 2003; Надлер, 2004]. К тому же такое исследование должно не руководствоваться принципом «уравнительного подхода», а давать конечное определение этому влиянию через опосредующий эффект ролей советов директоров и сдерживающий эффект контекста внешнего окружения фирмы.

\section{3. Компетенции директора и исполнение функций совета директоров}

Как было указано выше, большое количество исследований, связанных с проблемами, возникающими в работе советов директоров, были проведены вследствие того, что ученые так и не смогли установить четкую взаимосвязь между независимостью директоров и деятельностью фирмы. Именно по этой причине требуется обосновать необходимость появления принципиально новой концепции, которая должна строиться на анализе процессов, происходящих внутри советов директоров. В этой главе я охарактеризую основы выдвижения такой концепции и выскажу свои предложения относительно того, в каких направлениях следует проводить исследовательскую работу в будущем.

Вместе взятые знания, навыки и опыт входят в понятие «человеческий капитал». Когда они присутствуют в совете директоров, то представляют собой ценнейший ресурс фирмы. Человеческий капитал директоров остается недостаточно изученной областью менеджмента. Более того, человеческий капитал неисполнительных директоров практически не изучался. Тем не менее человеческий капитал является основой интеллектуального капитала и, таким образом, имеет неоспоримое влияние на способность директоров действовать в соответствии с интересами фирмы.

Одна из проблем, присущих попыткам установления связи между советами директоров и деятельностью фирмы, состоит в том, что сами советы сталкиваются с широким кругом задач и обязанностей. Для проведения исследования в будущем необходимо разделить многочисленные направления директорской идентификации и их влияний посредством целенаправленного фокусирования на их компетенциях и выполняемых ими ролях, особенно неисполнительными директорами.

Важный вопрос, который следует осветить в исследовании, - проводится ли подбор в состав совета директоров с учетом человеческого капитала неисполнительных директоров (компетенции) и действительно ли эти компетенции ведут к использованию их последними 
при осуществлении ими различных видов деятельности в совете и выполнении различных функций? Этот вопрос представляется важным, так как он отображает ценность неисполнительных директоров как руководителей, и будет зависеть от того, насколько неисполнительные директора способны правильно оценить ту или иную деловую ситуацию, в которой оказывается их фирма, и насколько правильными будут принимаемые ими в данной ситуации решения. С учетом того что компетенции неисполнительных директоров могут представлять собой важный актив совета директоров, становится непонятным, почему столь важный элемент совета почти не подвергался научному исследованию. Множество работ было посвящено применению теории человеческого капитала в отношении руководителей высшего звена [Кастаниас и Хелфат, 2001] и командам топ-менеджеров [Харви и др., 1994]. Но я думаю, что неисполнительные директоры заслуживают не меньшего внимания в силу присущих им особенностей, а именно их компетенций, так как те роли, которые выполняют в совете неисполнительные директора, в корне отличаются от ролей, выполняемых руководителями высшего ранга и командами топ-менеджеров в целом.

Таким образом, важной представляется задача дополнения процессноориентированного исследования моделью, связующей компетенции неисполнительных директоров и деятельность фирмы посредством тех ролей, которые они выполняют. С этой целью необходимо идентифицировать и классифицировать компетенции неисполнительных директоров, и эти компетенции должны быть проанализированы с точки зрения выполняемых функций.

Проведение исследования влияния на фирму неисполнительных директоров в свете выполняемых ими функций является важным, так как компетенции, необходимые для управления сложной и, возможно, большой организацией, в корне отличаются от тех, которые нужны для осуществления разработки стратегии фирмы. Более того, любой анализ влияния неисполнительных директоров на фирму должен признавать тот факт, что последние могут вносить свой вклад в деятельность фирмы несколькими способами: предоставляя доступ к ресурсам [Пфеффер, 1972], оказывая юридические и консультативные услуги [Кеснер и Джонсон, 1990] или разрабатывая корпоративную стратегию [МакНалти \&Петтигру, 1999]. Кратко говоря, понять, какой именно вклад вносят неисполнительные директоре, невозможно вне контекста тех ролей, которые они исполняют.

Каковы принципиально важные функции, которые выполняют неисполнительные директора в компании? Набор таких ролей сформировался с течением времени - в процессе работы и получил разностороннюю концептуальную трактовку различными исследователями [Ханг, 1998; Джонсон и др., 1996; Липтон \& Лорш, 1992]. В прошлом считалось, что неисполнительные директорf призваны играть «церемониальные» роли, и однажды они получили громкое сравнение с «украшениями на корпоративной рождественской елке» [Мэйс, 1971, с. 90]. Большинство людей, проводивших исследования, анализировали роль неисполнительного директора, базируясь на следующих исходных данных:

- поддержка в осуществлении управления;

- создание стратегии;

- контроль менеджмента;

- выполнение роли посредника между конкурирующими группами, такими как акционеры и другие посредники;

- «связующая» роль в соединении фирмы с ее внешним окружением.

Несмотря на широкий диапазон ролей, признаваемых исследователями, корпоративные скандалы последних лет послужили тому, что был сделан, по- видимому, неправильный акцент на роль неисполнительных директоров как контролирующего органа управления. Это является очевидным не только потому, что активно обсуждалось в прессе, но и потому, что нашло отражение в директивах, относящихся к проведению реформы управления [Хигз, 2003; NACD, 2000; OECD, 1999]. 
Поэтому я выдвигаю следующие гипотезы в отношении независимых директоров и тех ролей, которые они выполняют:

Гипотеза 1: Эффективность работы неисполнительного директора будет зависеть от успешного выполнения ряда функций совета директоров, а не только от эффективности выполнения одной контрольной функции.

Гипотеза 2: Эффективность независимого директора будет зависеть от уровня человеческого капитала, который он приносит с собой в совет директоров и которій проявляется в компетенциях.

Гипотеза 3: Компетенции независимых директоров дадут более точное объяснение тому, какое влияние оказывают независимые директора на деятельность и эффективность компании, а не определению степени их независимости и количественных соотношений исполнительных и независимых директоров в совете.

\section{4. Компетенции директоров и ориентация функций независимых директоров}

Быстрое развитие технологий и повышение глобализации фирм заостряют внимание на путях и способах, посредством которых фирмы повышают уровни своей конкурентоспособности. Традиционное стратегическое различие между «быть в форме» и «быть гибким» стало еще более отчетливым ввиду важности, придаваемой взгляду, основанному на ресурсах. Благодаря этому взгляду объяснялись самые эффективные средства конкурентной борьбы фирмы. Спор относительно того, состоит ли конкурентное преимущество в успешном взаимодействии фирмы с внешним окружением или в том, что она обладает уникальными ресурсами и возможностями, заложенными в ней самой, может касаться и роли неисполнительных директоров.

Традиционный взгляд на роль директоров утверждал, что исполнительные директоры вели бы операционную деятельность фирмы, в то время как взаимодействие с окружающим миром осуществлялось бы, до некоторой степени, неисполнительными членами совета. В свете основанного на компетенциях взгляда на роль неисполнительных директоров, который представлен здесь, традиционное выстраивание функций совета директоров подвергается сомнению. В то время как при более общем рассмотрении вопроса никто бы не отрицал справедливость такой классификации директорских функций, я представляю основу анализа, которая имеет больше нюансов и не подразделяет роли неисполнительных директоров в соответствии со столь четко очерченными рамками.

Традиционный подход к исследованию системы управления показал, что «традиционная» классификация стратегических ориентиров высших эшелонов управления фирмы была полезна; но эмпирические исследования, рассматривающие исполнительных директоров «ориентированными на фирму», не дали адекватного объяснения роли и влияния независимых директоров. Недостаток таких выводов, возможно, явился следствием проведения анализа ориентиров членов высшего руководства фирмы по принципу исключительно персонального положения, занимаемого ими в фирме: руководителей тестировали, основываясь на предположении, что они имеют «внутреннюю» ориентацию, а внешние директора - «внешнюю».

Представление анализа влияния независимых директоров на фирму в соответствии с директорскими компетенциями позволяет нам получить более ясную картину того, как и в каких обстоятельствах независимый директор оказывает воздействие на деятельность фирмы. В представленных здесь основах проведения анализа «стратегическая ориентация» директоров будет классифицирована в соответствии с их компетенциями. Здесь предлагается считать, что неисполнительный директор не имеет «внешней ориентации» по определению. Другими словами, не название определяет стратегическую ориентацию независимого директора, а те компетенции, которые он приносит с собой в фирму. 
Суммируя вышесказанное, я предлагаю считать, что параметры, определяющие уровень компетенции директоров, предоставят более правильную основу для определения того, как соотносятся внутренняя и внешняя ориентации директоров с деятельностью фирмы по сравнению с тем, что могут дать для анализа названия: директор «исполнительный» и «независимый».

Это приводит нас к следующему заключению.

Гипотеза 4: Параметры внутренней или внешней ориентации функций директоров, основанные на их компетенциях, находятся в более тесной связи с факторами, определяющими эффективность деятельности фирмы, чем параметры, основанные на их более грубой классификации, подразделяющей директоров на «внешних» или «внутренних».

\section{5. Влияние непредвиденных обстоятельств на роль независимого директора}

Представленная здесь основа подчеркивает важность включения возникновения непредвиденных обстоятельств. Если неисполнительные директорі в своїй деятельностии грают множество ролей, следует ожидать, что эти роли будут ограничены теми непредвиденными обстоятельствами, с которыми сталкивается сама фирма. Различные обстоятельства будут приводить к смещению акцентов среди ролей, исполняемых независимыми директорами. Любое исследование, основанное на компетенциях, должно будет принять этот факт во внимание. Компетенции, которыми владеет один независимый директор, могут оказаться чрезвычайно ценными для одной фирмы и менее ценными - для другой, в зависимости от тех уникальных обстоятельств, в которых находится каждая фирма.

В течение некоторого времени в исследованиях в области стратегического менеджмента придавалось большое значение тому, что ресурсы и структуры фирм должны соответствовать их внешнему окружению. Предыдущие работы выделяли роли независимых директоров как связующее звено между ними и финансовыми институтами, особенно в контексте первоначального публичного размещения акций компании [Хиггинс \& Гулати, 2000]. В общем, жизненный цикл организации оказался полезной характеристикой при определении влияния совета директоров на результаты деятельности фирмы. Предлагается, что жизненный цикл организации будет основной переменной, влияющей на компетенции, которые будут наиболее ценными в данное время для жизнедеятельности фирмы. Другие переменные, которые будут играть значительную роль, включают: размер компании, степень диверсифицированности ее продуктового портфеля, , опыт управленческой команды и волатильность отрасли.

Необходимость учета названных переменных в модели исследования, основанного на компетенциях директоров, ведет к следующей гипотезе.

Гипотеза 5: Как внешние, так и внутренние факторы будут влиять на соотношение между директорскими компетенциями и выполнение функций совета директоров.

\section{6. Заключение}

Ключ к улучшению совета директоров лежит... в компетенциях... индивидуальных директоров. Давид Надлер

Совет директоров является самым важным органом, принимающим решения. Понимание принципов влияния совета директоров на жизнедеятельность фирмы было и остается одной из чрезвычайно актуальных задач исследователей, занимающихся проблемами управления. Данная работа предлагает принципы модели проведения исследования совета директоров, которое включает анализ компетенции директоров и его функции , а также факторы, вытекающие из внешнего окружения фирмы.

Выпуск \#2(6), 2008 () Электронный журнал Корпоративные Финансы, 2008 
Развитие последующих исследований на основе изучения компетенций независимых директоров могло бы стать вызовом общепринятому взгляду, который утверждает, что вклад этих сотрудниковв деятельность фирмы зависит от их связей с окружающим миром. В то время как независимые директора являются формально аутсайдерами, их стратегическая ориентация и вклад в получение фирмой конкурентного преимущества могут быть основаны на их работе, направленной на внутренние процессы фирмы, для которой это имеет практические последствия: независимые директора, от которых ожидают выполнения комбинации как внутренних, так и внешних функций, могут не справиться с этой ролью, если их компетенции более ориентированы в сторону внутреннего распорядка работы фирмы.

Целью данной работы была разработка модели анализа, который предоставит исследователям возможность проверить, до какой степени вышеупомянутое высказывание исследователя Давида Надлера соответствует действительности. Одной из первых ступеней к нахождению ответа на вопрос, ведут ли компетенции директоров к повышению качества корпоративного управления, является задача формирования основных принципов оценки влияния компетенций независимых директоров на эффективность фирмы. Я особо выделяю группу независимых директоров, потому что значительное количество исследований было проведено в этом направлении, но почти все они были выполнены исключительно с позиции структуры совета, а не с позиции их компетенций. При помощи использования теории человеческого капитала, основанной ресурсной теории фирмы, в данной работе я пытался определить типы компетенций независимых директоров, которые оказывают наибольшее влияние на деятельность фирмы. Также я предлагаю изучить это влияние, не замыкаясь только на роли совета, а скорее посредством изучения набора ролей, что расширит понимание того, когда и в каких условиях независимые директора приносят наибольшую пользу фирмам, в которых они служат.

Прежние эмпирические работы, посвященные работе советов директоров, фокусировались на структуре этого органа, анализируя в основном состав совета и количество независимых директоров, чтобы установить факт влияния совета на деятельность фирмы. Результаты были далеко не убедительными. Отсутствие выводов побудило некоторых ученых сказать, что исследование советов директоров было слишком узким и слишком долгим и что следующее исследование должно фокусироваться на анализе процессов, происходящих в советах директоров. Некоторые ученые высказали точку зрения, что директорские компетенции вносят больший вклад в дело повышения эффективности работы правления, чем простое определение степени «директорской независимости», и призвали более целенаправленно исследовать директорские компетенции. Данная работа способствует проведению широкой дискуссии на тему влияния директорских компетенций на выполнение ими функций советов директоров и их воздействия на эффективность деятельности фирмы.

\section{Ссылки и библиография}

1. Aguilera Ruth. Corporate Governance and Director Accountability: An Institutional Comparative Perspective // British Journal of Management. 2005. No. 16. P,39-53.

2. Enhanced Corporate Governance Rules // American Stock Exchange. 2002. September 13.

3. Andrews K. The Concepts of Corporate Strategy. Homewood, IL: Dow Jones-Irwin. 1971.

4. Andrews K. Can the Best Corporations Be Made Moral? //Harvard Business Review. 1973. Vol. 51. No. 3. P. 57.

5. Association Française de la Gestion Financière. Recommandations sur le Gouvernement d'Entreprise:The Bouton Report. 2004.

6. Bain J.S. Barriers to New Competition. Cambridge: Harvard University Press, 1956.

7. Bain J.S. Industrial Organization. N.-Y.: Wiley, 1968. 
8. Barney J. B.. Firm Resources and Sustained Competitive Advantage// Journal of Management. 1991. No. 17. P. 99-120.

9. Barnhart S., Marr M. and Rosenstein S.. Firm Performance and Board Composition: Some New Evidence // Managerial and Decision Economics. 1994. Vol. 15. No. 4. P. 329-340.

10. Baysinger B.D. and Butler H.Corporate Governance and the Board of Directors: Performance Effects of Changes in Board Composition // Journal of Law, Economics and Organization. 1985. No. 1. P. 101-134.

11. Becker G.S. Human Capital: A Theoretical and Empirical Analysis: With Special Reference to Education // National Bureau of Economic Research. 1964.

12. Beasely M. An Empirical Analysis of the Relation between Board of Director Composition and Financial Statement Fraud // The Accounting Review. 1996. Vol. 71. No. 4. P. 443465.

13. Berle A.A. and G. Means. The Modern Corporation and Private Property. N.-Y.: MacMillan Publishing Company, 1932

14. Bhagat S. and B. Black. The Uncertain Relationship between Board Composition and Firm Performance // The Business Lawyer. 1999. Vol. 54. No. 3. P. 921-963.

15. Blake A. Dynamic directors: Aligning board structure for business success. Hampshire: MacMillan Press Ltd, 1999.

16. Bourgeois L.J. Performance and Consensus // Strategic Management Journal. 1980. Vol. III. No. 1. P. $227-248$.

17. Brown J.K. This Business of Issues: Coping with the Company's Environment. Conference Board. N.-Y.: 1979.

18. Byrd J. and Hickman K. Do Outside Directors Monitor Managers? Evidence from Tender Offer Bids // Journal of Financial Economics. 1992. Vol. 32. No. 2. P. 195-221.

19. Cannella A.A. \& Hambrick D.C. Effects of Executive Departures on the Performance of Acquired Firms // Strategic Management Journal. 1993. No. 14 (Special Issue). P. 137152.

20. Cannella A.A., Pettigrew A. \& Hambrick D.. Upper Echelons: Donald Hambrick on Executives and Strategy // The Academy of Management Executive. 2001. Vol. 15. No. 3. P. $36-44$.

21. Carpenter R.N.: 1988. "Corporate governance. part II: Directors responsibilities”. Directors \& Boards. 29. 3. 3-6.

22. Castanias. R.P. and C.E. Helfat: 2001. "The Managerial Rents Model: Theory and Empirical Analysis". Journal of Management. 27. 6: 661-678.

23. Chandler. A.D. 1962. Strategy and Structure. Cambridge. MA: MIT Press.

24. Coase. R.H.. 1937. The Nature of the Firm. Chicago: The University of Chicago Press

25. Committee on the Financial Aspects of Corporate Governance: 1992. Report of the Committee on the Financial Aspects of Corporate Governance (Cadbury Report). Burgess Science Press. London.

26. Conseil National du Patronat Français. Association Française des Entreprises Privées. The Board of Directors of Listed Companies in France (July 10. 1995) [The Viénot Report].

27. Copeland. M.T. and A.R. Towl. The Board of Directors and Business Management. Andover Press. Andover. MA. 1947.

28. Corley. K.G.: 2005. "Examining the Non-Executive's Role from a Non-Agency Theory Perspective: Implications Arising from the Higgs Report”. British Journal of Management. Vol. 16. S1-S4.

29. Cyert. R.M.. \& March. J.G. 1963. A Behavioral Theory of the Firm. Englewood Cliffs. NJ: Prentice-Hall.

30. Daily. C.M. and D.R. Dalton: 1992. "The Relationship Between Governance Structure and Corporate Performance in Entrepreneurial Firms". Journal of Business Venturing. 17. 5: 375-386. 
31. Daily. C.M. and D.R. Dalton: 1997. "CEO and Board Chair Roles Held Jointly or Separately: Much Ado About Nothing?” Academy of Management Executive. 11. 3: 1120.

32. Daily. C.M.. D.R. Dalton. C.R. Cannella: 2003. "Introduction to Special Topic Forum Corporate Governance: Decades of Dialogue and Data". Academy of Management Review. 28. 3: 371-382.

33. Dalton. C.M. \& D. R. Dalton: 2005. "Boards of Directors: Utilizing Empirical Evidence in Developing Practical Prescriptions". British Journal of Management. 16. S91 - S97.

34. Dalton. D.R.. C.M. Daily. A.I. Ellstrand \& J.L. Johnson: 1998. "Meta-Analytic Reviews of Board Composition. Leadership Structure. and Firm Performance". Strategic Management Journal. 19. 3: 269-290.

35. Dalton. D.R.. C.M. Daily. A.I. Ellstrand \& J.L. Johnson: 1999. "Number of Directors and Financial Performance: A Meta-Analysis”. Academy of Management Journal. 42. 6: 674686.

36. Finkelstein. S.. \& Hambrick. D. 1996. Strategic Leadership. Saint Paul: West Educational Publishing.

37. Forbes. D.P. and F.J. Milliken: 1999. "Cognition and Corporate Governance: Understanding Boards of Directors as Strategic Decision-Making Groups". The Academy of Management Review. 24. 3: 489-505.

38. Fosberg. R.: 1989. "Outside Directors and Managerial Monitoring". Akron Business and Economic Review. 20. 2: 24-32.

39. Gibbs. P.: 1993. "Determinants of Corporate Restructuring: Takeover Threat and Free Cash Flow". Strategic Management Journal. 14: 51-68.

40. Gillies. J. and R. Leblanc: 2003. "The Coming Revolution in Corporate Governance". Ivey Business Journal. 68. 1.

41. Grace. M.. A. Ireland. and K. Dunstan: 1995. "Board Composition. Non-Executive Directors' Characteristics and Corporate Financial Performance". Asia-Pacific Journal of Accounting. 2: 121-137.

42. Hambrick. D. and P. Mason: 1984. "Upper Echelons: The Organization as a Reflection of Its Top Managers". Academy of Management Review. 9. 193-206.

43. Hendry. J.: "Beyond Self-Interest: Agency Theory and the Board in a Satisficing World". British Journal of Management. 16. Special Issue. pp. S55-S63.

44. Heracleous. L.: 2001. "What is the Impact of Corporate Governance on Organisational Performance". Corporate Governance: An International Review. 9. 3. 165-173.

45. Hermalin. B.E. and M.S. Weisbach: 1991. "The Effects of Board Composition and Direct Incentives on Firm Performance". Financial Management. 20. 4: 101-112.

46. Hermalin. B.E. and M.S. Weisbach: 2000. "Boards of Directors as an Endogenously Determined Institution: A Survey of the Economic Literature". SSRN Electronic Paper Series.

47. Higgins. M.C. \& R. Gulati: 2000. "Getting off to a Good Start: the Effects of Upper Echelon Affiliations on Prestige on Investment Bank and IPO Success". paper presented at the Academy of Management Conference. Toronto.

48. Higgs. D.: 2003. "Review of the Role and Effectiveness of Non-Executive Directors". Department of Trade and Industry. London.

49. Hill. C.W. \& S.A. Snell: 1988. "External Control. Corporate Strategy. and Firm Performance in Research Intensive Industries". Strategic Management Journal. 9. 6: 577590.

50. Hung. H.: 1998. "A Typology of the Theories of the Roles of Governing Boards". Corporate Governance: An International Review. 6. 2: 101-111.

51. Johnson. J.L. C.M. Daily. A.E. Ellstrand: 1996. "Boards of Directors: A Review and Research Agenda". 22. 3: 409-438. 
52. Judge. W.Q. \& C.P. Zeithaml: 1992. "Institutional and Strategic Choice Perspectives on Board Involvement in the Strategic Decision Process". Academy of Management Journal. 35. 4: 766-794.

53. Kesner. I.F. \& R.B.Johnson: 1990. "An Investigation of the Relationship between Board Composition and Stockholder Suits". Strategic Management Journal. 11. 4: 327-336.

54. Kiel. G.C. and G.J Nicholson: 2002. "Real World Governance: Driving Business Success through Effective Corporate Governance". Monash Mount Eliza Business Review. 5: 1728 .

55. Koontz. H. 1967. The Board of Directors and Effective Management. McGraw-Hill. New York.

56. Korn/Ferry International. Boards of Directors: Ninth Annual Study. New York. February 1982.

57. Kosnik. R.: 1990. "Effects of Board Demography and Directors' Incentives on Corporate Greenmail Decisions". Academy of Management Journal. 33. 1: 129-150.

58. Lavelle. L.: 2002. "Enron: How Governance Rules Failed". Business Week. Vol. 21. No. 3766. pp. 28-29.

59. Leblanc. R.: 2004. "Preventing Future Hollingers". Ivey Business Journal Online. London: Sep/Oct 2004. pg. B1.

60. Lipton. M. \& J.W. Lorsch: 1992: "A Modest Proposal for Improved Corporate Governance". Business Lawyer. 48. 1: 59-77.

61. Mace. M.L.G (1971). Directors: Myth and Reality. Division of Research. Graduate School of Business Administration. Harvard University. Boston. MA.

62. Mason. E.S.: 1939. "Price and Production Policies of Large Scale Enterprises". American Economic Review. 29: 61-74.

63. March. J.C.. \& Simon. H.A. 1958. Organizations. New York: Wiley

64. McNulty. T. and A. Pettigrew: 1996. "The Contribution. Power. and Influence of Part-time Board Members". Corporate Governance: An International Review. 4. 3.

65. McNulty. T. and A. Pettigrew: 1999. "Strategists on the Board". Organization Studies. 20. 1: 47-74.

66. McNulty. T.. J. Roberts and P. Stiles. 2003. Creating Accountability within the Board: The Work of the Effective Non-Executive Director. Department of Trade and Industry/HMSO. London.

67. McNulty. T.. J. Roberts and P. Stiles: 2005. "Undertaking Governance Reform and Research: Further Reflections on the Higgs Review". British Journal of Management. 16. Special Issue. pp. S99-S107.

68. Molz. R.: 1988. "Managerial Domination of Boards of Directors and Financial Performance". Journal of Business Research". 16: 235-249.

69. NACD Blue Ribbon Commission (2000). Report of the NACD Blue Ribbon Commission on the Role of the Board in Corporate Strategy. National Association of Corporate Directors. Washington. D.C.

70. Nadler. D.: 2004. "Building Better Boards". Harvard Business Review. 82. 5: 102-117.

71. Nahapiet. J. and S. Ghoshal: 1998. "Social Capital. Intellectual Capital. and the Organizational Advantage". Academy of Management Review. 23. 2: 242-266.

72. NASDAQ (2002). Corporate Governance Proposals. NASDAQ. New York. NY. September 13.

73. New York Stock Exchange (2002). Corporate Governance Rule Proposals. New York Stock Exchange. New York. NY.

74. Nicholson. G.J. and G.C. Kiel: 2004. "Breakthrough Board Performance: How to Harness Your Board's Intellectual Capital”. Corporate Governance. 4. 1: 5-23.

75. Nussbaum. B.: 2002. "Can Trust Be Rebuilt? America is in shock. but the corporate cleanup is well under way". Business Week. 8 July. p. 32. 
76. OECD Ad Hoc Task Force on Corporate Governance (1999). OECD Principles of Corporate Governance. OECD. Paris.

77. OECD (2004). OECD Principles of Corporate Governance. OECD. Paris.

78. Pearce. J.A.: 1983. "The Relationship of Internal versus External Orientations to Financial Measures of Strategic Performance". Strategic Management Journal. 4. 4: 297-306.

79. Pearce. J.A. and S.A. Zahra: 1991. "The Relative Power of CEOs and Boards of Directors: Associations with Corporate Performance”. Strategic Management Journal. 12. 2: 135-153.

80. Penrose. E.T. 1959. The Theory of the Growth of the Firm. New York: Wiley.

81. Pettigrew. A.: 1992. "On Studying Managerial Elites". Strategic Management Journal. 13. 163-182.

82. Pettigrew. A.M. and R. Whipp 1991. Managing Change for Competitive Success. Oxford: Basil Blackwell. Ltd.

83. Pfeffer. J.: 1972. "Size and Composition of Corporate Boards of Directors: the Organization and Its Environment". Administrative Science Quarterly. 2. 218-228.

84. Pfeffer. J. and G.R. Salanczik. 1978. The External Control of Organizations: A Resource Dependence Perspective. Harper and Row. New York. NY.

85. Porter. M.E. 1980. Competitive Strategy. New York: Free Press.

86. Porter. M.E. 1985. Competitive Advantage. New York: Free Press.

87. Pye. A. \& A. Pettigrew: 2005. "Studying Board Context. Process and Dynamics: Some Challenges for the Future". British Journal of Management. 16. S27 - S38.

88. Quinn. J.B.: 1977. "Strategic Goals: Process and Politics". Sloan Management Review. 23. pp. 21-37.

89. Rhoades. D.L.. P.L. Rechner \& C. Sundaramurthy: 2000. "Board Composition and Financial Performance: A Meta-Analysis of the Influence of Outside Directors". Journal of Managerial Issues. 12. 1: 76-91.

90. Roberts. J. T. McNulty \& P. Stiles: 2005. "Beyond Agency Conceptions of the Work of the Non-Executive Director: Creating Accountability in the Boardroom". British Journal of Management. 16. S5 - S26.

91. Schellenger. M. Wood. D. \& A. Tashakori: 1989. "Board of Director Composition. Shareholder Wealth. and Dividend Policy". Journal of Management. 15. 3: 457-467.

92. Schmidt. R.: 1975. “Does Board Composition Really Make a Difference?". The Conference Board Record. October. pp. 38-41.

93. Securities and Exchange Commission (2003b). NASD and NYSE Rulemaking: Relating to Corporate Governance. Release No. 34-48745. Securities and Exchange Commission. Washington. D.C.. December $1^{\text {st }}$.

94. Selznick. P. 1957. Leadership in Administration: A Sociological Interpretation. New York: Harper \& Row.

95. Shleifer. A. and R. Vishny: 1997. "A Survey of Corporate Governance". Journal of Finance. 52: 737-783.

96. Simon. H.A. 1945. Administrative Behavior. New York: Macmillan.

97. Tricker. R.I. (Ed.): 2000. Corporate Governance. Ashgate. Aldershot; Brookfield. USA.

98. United States Congress (2002). Sarbanes-Oxley Act of 2002. $107^{\text {th }}$ Congress of the United States of America. H.R. 3763. US Government Printing Office. Washington. D.C.

99. Vance. Stanley C.: 1978. "Corporate Governance: Assessing Corporate Performance by Boardroom Attributes". Journal of Business Research. 6: 203-220.

100. Vance. Stanley C. 1983. Corporate Leadership: Boards. Directors. and Strategy. McGraw-Hill Series in Management. McGraw-Hill. New York. NY.

101. Weir. C.: 1997. "Acquisitions and Firm Characteristics: the Importance of Internal Monitoring Mechanisms". Management Decision. 35. 2: 155-165.

102. Westphal. J.D.: 1999. "Collaboration in the Boardroom: Behavioural and Performance Consequences of CEO - Board Social Ties". Academy of Management Journal. 42. 1: 7 24. 
103. Westphal. J.D.: 2002. "Second Thoughts on Board Independence: Why Do So Many Demand Board Independence When It Does So Little Good?". The Corporate Board. Sept./Oct. 6-10.

104. Yermack. D.: 1986. "Higher Market Valuation with a Small Board of Directors". Journal of Financial Economics. 40: 186-211.

105. Zahra. S.: 1990 "Increasing the board's involvement in strategy". Long Range Planning. 23. 109-117.

106. Zahra S. A. and J. A. Pearce: 1989. "Boards of Directors and Corporate Financial Performance: A Review and Integrative Model". Journal of Management. 15. 2: 291-334. 